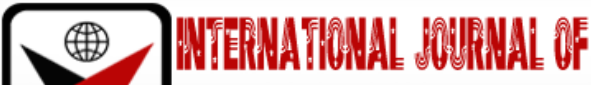

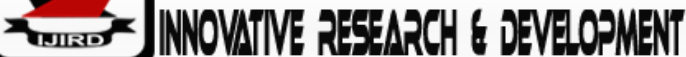

ISSN 2278-0211 (Online)

\section{Bio-Assay Guided Fractionation and Isolation Of Anti-inflammatory Compound from Crataevaadansonii Stem Bark Extract}

\author{
Dr. Ezenwali, Moses. Obinna \\ Lecturer, Department of Applied Biochemistry, \\ Enugu State University of Science and Technology, Nigeria \\ Njoku, U.Obioma \\ Professor, Department of Biochemistry, University of Nigeria, Nigeria \\ Okoli, Charles 0. \\ Professor, Department of Pharmacology and Toxicology \\ University of Nigeria, Nigeria
}

\begin{abstract}
:
This study is aimed at fractionating and isolation of the anti-inflammatory bioactive compound of Crataevaadansonii stem bark extract. The stem bark powder $(7.147 \mathrm{~kg})$ was extracted with $1: 1$ ( $\mathrm{v} / \mathrm{v})$ mixture of dichloromethane/methanol in a soxhlet apparatus $\left(60^{\circ} \mathrm{C}\right)$. The extract obtained was successively fractionated with $n$ hexane, ethylacetate, dichloromethane and methanol (100\%). The extract and fractions were subjected to biological activity-guide studies for anti-inflammatory activity using the egg-albumin induced rat hind paw edema method as activity-guide. Ethylacetate fraction, the most active was subjected to further separation in silica gel column eluted with graded mixtures of $n$-hexane and ethylacetate which afforded different ethylacetate sub-fractions. Standing EF2 sub-fraction under reduced temperature $\left(4^{\circ} \mathrm{C}\right)$ yielded a white crystalline solid (C.adansonii Compound; CA1 identified as triterpene). The extract was further subjected to formaldehyde-induced chronic inflammation tests in rats. The stem bark powder, extract, and fractions were subjected to qualitative and quantitative phytochemical analyses using standard protocols. The extract at a lower dose exhibited stronger reduction on the global edematous response due to arthritis.
\end{abstract}

Keywords: Crataevaadansonii, Anti-inflammatory activities, TRPA1

\section{Introduction}

Alteration in normal biochemical processes in a living tissue brought about by its response to both endogenous and exogenous stimuli, including physical stimulation such as change in temperature, pressure, $\mathrm{pH}$, radiation, pathogens and chemical substances released by immune cells (inflammatory mediators) bradykinin, histamine, cytokines, hormones, change in available nutrients and abnormal partial pressure of oxygen (Gonzalez-Muniesa et al., 2015), as well as other environmental stresses, are one of the survival mechanisms of a living cell. However, inflammatory pathways play crucial roles in these biochemical processes. Inflammation defined as the body tissue response to injury (infection, trauma and hypersensitivity) is characterized in the acute phase by increase in the blood flow to the inflamed tissue caused by vasoactive-dependent vascular permeability mediators (nitric oxide (NO), prostacyclin, endothelin and endothelialderived hyperpolarizing factor) synthesized and released by endothelial cells leading to junctional opening and gap formation between endothelial cells which allows leakage of plasma and blood fluids (Galley \& Webster, 2004). Moreover, while chemokines released by phagocytic cells recruit immune cells (leukocytes) to the inflammatory sites via increased expression of cellular adhesion molecules, their second important substances, cytokines (IL-1, IL-6, IL-8, IL-12, TNF-, NF$\mathrm{kb}$ ) activate cellular immunity (Charles A Janeway, 2001). Nitric Oxide plays a pivotal role in the maintenance of cardiovascular homeostasis (Ritchie, Drummond, Sobey, De Silva, \& Kemp-Harper, 2017). Its biosynthesis at high concentration by inducible nitric oxide synthase stimulates inflammation and induces apoptosis (Takasugi, 1993). Reactive oxygen species (ROS) mediates loss on NO bioavailability and functions via a non-enzymatic direct inactivation. Chronic inflammation is characterized by the development of specific humoral and cellular immune responses to the pathogens present at the site of tissue injury. These biochemical and cellular alterations are regulated by inflammatory mediators. In the last decade, intensive research into the mechanisms of inflammation has implicated several inflammatory triggering factors (infection, oxidative stress, PAMP, DAMP, radiation, thermal, chemicals, toxins, trauma/injury, hypersensitivity and immune response) and biochemical pathways (C-reactive protein synthesis, cyclooxygenase (COX) -1 and -2, lipoxygenase, nuclear factor kappa-B, tumor necrosis factor- $\alpha$, adhesion molecules, nitric 
oxide synthesis, reactive oxygen species generation, cytokines and collagenase) with the production of prostanoids and reactive oxygen species as central to the progression of many inflammatory diseases (Chen et al., 2018). Free arachidonic acids released from traumatized cellular membranes by the catalytic action of phospholipase $\mathrm{A}_{2}$ serve as substrates for the three major groups of inflammatory enzymes, prostaglandin $\mathrm{G} / \mathrm{H}$ synthases, lipoxygenase or epoxygenases resulting in the biosynthesis of prostaglandins (PGs), thromboxane $A_{2}$, the leukotrienes, or epoxyeicosatrienoic acids (Jang, Kim, \& Hwang, 2020). Inflammatory stimulus creates a dramatic imbalance in the homeostasis of prostaglandin (Ricciotti \& FitzGerald, 2011). Increased prostaglandins and paracrine/autocrine hormones, released by cells of the body induce sickness-like behaviors once released in the intracellular space (Maroon-Lango, Schneider, Turner, Presting, \& Alvarez, 2010).

The therapeutic potentials of both steroidal and non-steroidal anti-inflammatory drugs could be attributed to their peculiar ability to inhibit several inflammatory triggering factors and inflammatory biochemical pathways, especially the production of prostaglandins by the enzymatic action of COX. Within Enugu metropolis (Eastern Nigeria), the stem bark extract of $C$. adansoniiis used in the treatment of arthritis, a disorder of chronic inflammation as well as soft tissue swellings and pains. C. adansonii, a well-known Nigerian medicinal plant, has been used by traditional medicine practitioners in the management of chronic diseases such as rheumatism, arthritis, and gout (Gieling et al., 2009). This species that is restricted to Africa has a very close similarity with the Asian CratevareligiosaForst. F. which most authors have failed to distinguish (Igoli et al., 2014). In traditional medicine, the stem bark is applied externally to relieve pain in joints. The fresh juice of C.adansonii leaves is used for the relief of earache and toothache (Gieling et al., 2009). Powder of the bark is used in rheumatism, itches, epilepsy, asthma (Kanase, Patil, \& Kanase, 1994). Water and alcohol decoctions of the leaves are used in managing inflammatory diseases such as rheumatoid arthritis (Ogbole \& Ajaiyeoba, 2010). It is believed to possess tonic properties and used as a counter-irritant for headaches. Available experimental evidence showed that extracts of the leaves caused moderate anti-trypanosomal activity (Igoli et al., 2014) and marked inhibition of xanthine oxidase activity (Udeh \& Onoja, 2015).

\section{Materials and Methods}

\subsection{Animals}

Adult male albino rats (150-250 g) were obtained from the animal house of College of Medicine, University of Nigeria, Enugu Campus. The animals were housed in steel cages within the Laboratory Facility of BrainPhosphorylationship Scientific Solution Services, Enugu, Nigeria and maintained on standard feed and clean drinking water ad libitum. They were allowed to acclimatize for a period of four weeks before use. All animal experiments were in compliance with the National Institute of Health Guide for Care and Use of Laboratory Animal.

\subsection{Identification and Collection of Plant Materials}

Fresh stem barks of $C$. adansonii DC (Capparidaceae) were collected from plants used as hedge in Enugu North Local Government Area, Enugu State, Nigeria. The plant material was identified and authenticated by Mr. Alfred Ozioko of the International Centre for Ethnomedicine and Drug Development (InterCEDD) Nsukka, Enugu State, Nigeria. The voucher of the specimen (INTERCEDD 1047) was deposited at herbarium of InterCEDD.

\subsection{Preparation and Extraction of Plant Material}

The stem bark was cut into smaller pieces, dried away from direct sunlight at room temperature and pulverized to coarse powder using a Hammer mill (Gallenkamp, U.S.A.). A quantity, $7.147 \mathrm{~kg}$ of the dried stem bark was extracted with 1:1 mixture of dichloromethane/methanol in a soxhlet apparatus at $65^{\circ} \mathrm{C}$. The mixture was vacuum-filtered through Whatman No 1 filter paper and concentrated using a vacuum rotary evaporator to afford the extract. The percentage yield of the extract was calculated using the relation: Yield $(\%)=[\text { Weight of extract }(\mathrm{g}) / \text { Weight of plant material }(\mathrm{g})]^{*} 100$

\subsection{Determination of the Mineral Content of the Extract and Stem Bark}

\subsubsection{Digestion of the Samples}

The stem bark and extract were assayed for their mineral contents. The plant material and extract were ash in a furnace at $500^{\circ} \mathrm{C}$ and $10 \mathrm{ml}$ of $\mathrm{HNO}_{3}(50 \%)$ was added to $1 \mathrm{~g}$ of ground ash each. The solutions were boiled on a hot plate for $30 \mathrm{~min}$. After cooling, $\mathrm{H}_{2} \mathrm{O}_{2}(10 \mathrm{ml})$ and $10 \mathrm{ml}$ of distilled/dionized water were added to each. The mixtures were placed back on hot plate and boiled until their colour changed or those acids boiled off. The whole content were transferred into $50 \mathrm{ml}$ volumetric flask each and made up to the mark with distilled/dionized water.

\subsubsection{Determination of Mineral Contents of the Samples}

The mineral contents of the digested stem bark and extract were estimated using atomic absorption spectrophotometer (AAS). The digested samples aspirated by a tiny tube were heated to a high temperature, so that compound and molecules were converted into free atoms (a process called atomization). Light of specific wavelength (e.g. $450 \mathrm{~nm}$ for $\mathrm{Ca}$ ) emitted from a hollow cathode tube lamp is passed through the flame which contains free atoms that have been generated by heat-dissociation of the different molecules/compounds present in the sample. Any atom of the element that is excited at that specific wavelength $(450 \mathrm{~nm})$ will selectively absorb the radiation. The unabsorbed light beam then enters monochromator tuned to the same specific wavelength. The detector measures the light intensity after adjusting to zero with the blank. The absorption behaviour follows Beer's Law. Thus, absorbance (A) of standards and samples were measured and concentrations determined using the Beer-Lambert law $(A=a b c)$. 
Where $\mathrm{A}$ is the absorbance

- Is the molar absorptivity with units of $1 \mathrm{~mol}-1 \mathrm{~cm}-1$

- Is the path length of the sample - that is, the path length of the cuvette in which the sample is contained.

- Is the concentration of the compound in solution, expressed in mol l-1

\subsection{Acute Toxicity Studies}

The acute toxicity of the extract i.e. median lethal dose $\left(\mathrm{LD}_{50}\right)$ was determined according to the OECD 2008 guideline No. 425 (Acute Oral Toxicity-Up and Down-Procedure). Male albino rats (120 - 150 g) were used for this study. In the first stage of this test, animals received oral administration of 1000 and $2000 \mathrm{mg} / \mathrm{kg}(\mathrm{n}=5)$ of the extract and were observed for $24 \mathrm{~h}$ for deaths. Since no death occurred in any of the groups in this stage, 3000 and $5000 \mathrm{mg} / \mathrm{kg} \mathrm{doses} \mathrm{of} \mathrm{the}$ extract were administered to a fresh batch of animals $(n=5)$. The treated animals were under observation for 14 days for mortality and general behavior.

\subsection{Membrane Stabilization Activity}

The membrane stabilization activities of the fractions were studied in-vitro using hypotonicity-induced hemolysis of human red blood cells.

\subsubsection{Preparation of Erythrocyte Suspension}

Fresh whole ox-blood (10 ml) was collected, transferred to heparinized centrifuge tubes, centrifuged at $3000 \mathrm{rpm}$ for $5 \mathrm{~min}$, and washed three times with equal volume of normal saline. The volume of the blood was measured and reconstituted as a $40 \%(\mathrm{v} / \mathrm{v})$ suspension with isotonic buffer solution (10 mM sodium phosphate buffer pH 7.4). The composition of the buffer solution (g/L) was $\mathrm{NaH}_{2} \mathrm{PO}_{4}(0.2), \mathrm{Na}_{2} \mathrm{HPO}_{4}$ (1.15) and $\mathrm{NaCl}(9.0)$ (Shinde et al., 1999).

\subsubsection{Hypotonicity-Induced Hemolysis}

The hypotonic solutions (distilled water) (5 ml) containing 250, 500 and $1000 \mu \mathrm{g} / \mathrm{ml}$ concentrations of the fractions were put in 2 pairs (per concentration) of centrifuge tubes. Control tubes contained 5 ml of the vehicle (distilled water) or Diclofenac (250, 500 and $1000 \mu \mathrm{g} / \mathrm{ml})$. While the isotonic buffer solutions (5 ml) containing 250, 500 and 1000 $\mu \mathrm{g} / \mathrm{ml}$ concentration of fractions were put in 2 pairs (per concentration) of centrifuge tubes and isotonic control tubes contained $5 \mathrm{ml}$ of buffer solution or Diclofenac $(250,500$ and $1000 \mu \mathrm{g} / \mathrm{ml})$. Erythrocyte suspension $(0.05 \mathrm{ml})$ was added to each tube and after gentle mixing, the mixtures were incubated for $1 \mathrm{~h}$ at room temperature $\left(31^{\circ} \mathrm{C}\right)$. After incubation, the reaction mixture was centrifuged for $3 \mathrm{~min}$ at $1300 \mathrm{rpm}$ and the absorbance (OD) of the supernatant measured at $540 \mathrm{~nm}$ using Spectrophotometer. The inhibition (\%) of hemolysis was calculated using the relation (Shindeet al., 1999) [14];

Inhibition of haemolysis $(\%)=100\left[1-\left\{\left(\mathrm{OD}_{2}-\mathrm{OD}_{1}\right) /\left(\mathrm{OD}_{3}-\mathrm{OD}_{1}\right)\right\}\right]$

Where $\mathrm{OD}_{1}=$ absorbance of test sample in an isotonic solution

Where $\mathrm{OD}_{2}=$ absorbance of test sample in hypotonic solution

Where $\mathrm{OD}_{3}=$ absorbance of control sample in a hypotonic solution.

\subsection{Bio-Assay Guided Fractionation}

Egg-albumin induced rat hind paw-edema method of Winter et al., (1962) was used as an activity guide in the fractionation of the bioactive constituents (Winter, Risley, \& Nuss, 1962). The extract (300 g) was subjected to solventguided fractionation in a silica gel (60-120 mesh size) column successively eluted with n-hexane, ethyl acetate, dichloromethane, and methanol (100\%). The solvent fractions were collected in large volumes and concentrated in rotary evaporator under vacuum to yield the n-hexane fraction (nHF; Y g: X\% w/w), ethyl acetate fraction (EF; Y g: X\% w/w), dichloromethane fraction (DF; Y g: X\% w/w), and methanol fraction (MF; Y g: X\% w/w). The extract and fractions were screened for anti-inflammatory activity using the activity guide. Ethylacetate fraction was found to be the most active fraction. Consequently, the ethyl acetate fraction (81.32 g) was subjected to further separation in silica gel (60-120 mesh size) column eluted with graded mixtures of $n$-hexane and ethyl acetate $(1: 0 ; 9: 1 ; 8: 2 ; 6: 4 ; 4: 6 ; 5: 5)$. The sub-fractions were collected in $100 \mathrm{ml}$ volumes. The sub-fractions were concentrated and upon standing at reduced temperature $\left(4^{\circ} \mathrm{C}\right)$, the hexane: ethyl acetate (9:1) sub-fraction yielded a white colored crystalline powder (C. adansonii compound 1 (CA1); $1.44 \mathrm{~g} ; 1.77 \% \mathrm{w} / \mathrm{w}$ ) screening of CA1 for biological activity using the activity-guide confirmed its anti-inflammatory activity.

Where Yg = weight in gram

$\mathrm{X} \% \mathrm{w} / \mathrm{w}=$ Percentage yield

\subsection{Quantitative and Qualitative Phytochemical Screening}

The extract and fractions were both subjected to quantitative and qualitative phytochemical screening using standard phytochemical methods as outlined by Harborne(Harborne, 1998; Siddiqui \& Khan, 1997) and Trease and Evans (Trease, G.E. 1983) 


\subsection{In-Vivo Assays}

\subsubsection{Studies on Acute Inflammation}

\subsubsection{Systemic Acute Edema of the Rat Paw}

The effects of extract, fractions, and CA1 on systemic acute edema were studied using the rat paw edema method of Winter et al. (1962). Acute inflammation was measured in terms of change in volume of the rat hind paw induced by sub-plantar injection of fresh egg albumin [20]. The animals $(n=4)$ received $500 \mathrm{mg} / \mathrm{kg}$ of the extract, $\mathrm{nHF}, \mathrm{EF}$, and $\mathrm{MF}$, whereas DF and CA1 were administered at 100 and $200 \mathrm{mg} / \mathrm{kg}$. Control groups received either equivalent volume of the vehicle (3\% Tween-80) or Ibuprofen $(100 \mathrm{mg} / \mathrm{kg})$. Treatments were administered intraperitoneal. Edema formation was assessed in terms of the difference in the zero time paw volume of the injected paw and its volume at different times after egg-albumin injection. Percentage inhibition of edema was calculated using the relation (Perez, 1996) (Perez, 1996):

Inhibition of Edema $(\%)=100[1-(a-x) /(b-y)]$

Where $\mathrm{a}=$ mean paw volume of treated rats after egg albumin injection;

$\mathrm{x}=$ mean paw volume of treated rats before egg albumin injection;

$\mathrm{b}=$ mean paw volume of control rats after egg albumin injection;

$\mathrm{y}=$ mean paw volume of control rats before egg albumin injection;

Inflammation $=$ Average paw volume at time $\mathrm{t}$ - Average paw volume at zero time.

$\%$ Inflammation $=($ Average inflammation of treated group at time $\mathrm{T}) /($ Average inflammation of control at the same time $)$ $* 100$.

\subsubsection{Studies on Chronic Inflammation}

\subsubsection{Formaldehyde Arthritis Test}

The effect of the extract on chronic inflammation was assessed using arthritis induced by formaldehyde in rats (Chinnasamy et al., 2019). On day one, male adult albino rats ( $\mathrm{n}=4$ ) received the extract $(200 \mathrm{and} 500 \mathrm{mg} / \mathrm{kg})$ administered intraperitoneal. Control animals received either equivalent volume of vehicle (3\% Tween-80) or standard drugs (acetylsalicylic acid $100 \mathrm{mg} / \mathrm{kg}$ and dexamethazone $1 \mathrm{mg} / \mathrm{kg}$ ). One hour later, arthritis was induced by sub-plantar injection of $0.1 \mathrm{ml}$ of $2 \%$ formaldehyde solution. The same process was repeated on day 3 . Arthritis was assessed by measuring the diameter of the paw using a vernier caliper and the volume of the paw by mercury displacement method. Measurements were taken before induction and once daily for 10 days after induction of arthritis. The global edematous response to formaldehyde arthritis was quantified as the area under the curve (AUC) of the time-course of the arthritis event. The AUC was calculated using the trapezoidal rule. The level of inhibition of arthritis was calculated using the relation:

Inhibition of arthritis (\%) $=[1-($ AUCt $/ A U C c)] 100$

Where AUCc = AUC of the control group;

AUCt $=$ AUC of the treated group.

\subsubsection{Effect of Extract on Haematological Indices in Arthritis}

Chronic intraperitoneal administration of extract caused different effects on the levels of hematological parameters assayed in relation to the baseline values (Tables 13 and 14). The extract at varying concentrations caused significant $(\mathrm{p}<0.05)$ decrease in neutrophil counts. Conversely, WBC and lymphocyte counts were significantly $(\mathrm{P}<0.05)$ increased. The extract caused a slight decrease in the $\mathrm{Hb}$ and PCV levels as well as a moderate increase in the platelet counts.

\subsubsection{Effect of extract on Serum Electrolytes}

Chronic intraperitoneal administration of dichloromethane/methanol extract caused different effects on serum electrolyte concentrations of treated animals (Table 15). The extract caused significant $(\mathrm{P}<0.05)$ increase in serum selenium and copper concentrations. The extract also caused a moderate decrease in the serum concentration of zinc. Dexamethasone caused a significant $(\mathrm{P}<0.05)$ decrease in serum selenium concentration and increase in serum copper concentration.

\subsection{Statistical Analysis}

The data were recorded as means \pm standard deviation and analyzed by SPSS. One-way analysis of variance was performed by ANOVA procedures. Significant differences between means were determined by Duncan's multiple range tests. $\mathrm{p}<0.05$ was regarded as significant and $\mathrm{p}>0.05$ was non-significant.

\section{Results}

\subsection{Yield of Extraction, Fractionation and Sub-Fractionation}

The extraction process yielded (Extract; $375.17 \mathrm{~g}: 5.25 \% \mathrm{w} / \mathrm{w}$ ) of dichloromethane/methanol extract. Fractionation of the extract yielded the n-hexane fraction (nHF; $69.72 \mathrm{~g}: 18.58 \% \mathrm{w} / \mathrm{w}$ ), ethylacetate fraction (EF; $81.32 \mathrm{~g}$ : 21.68\% w/w), dichloromethane fraction (DMF; $02.67 \mathrm{~g}: 0.71 \% \mathrm{w} / \mathrm{w}$ ), and methanol fraction (MF; 22.47 g: $5.99 \% \mathrm{w} / \mathrm{w}$ ). 
Sub-fractionation of the ethylacetate fraction EF with hexane: ethylacetate (9:1) yielded a white colored crystalline powder at 4으 (C. adansonii compound 1 (CA1); $1.44 \mathrm{~g} ; 1.77 \% \mathrm{w} / \mathrm{w})$.

\subsection{Mineral Composition of the Stem Bark and Extract}

Table 7 shows the quantitative mineral composition of both the dried stem bark and the dichloromethane/methanol extract. Mineral analysis of the stem bark showed the presence of selenium (1.30 $\pm 0.05 \mathrm{ppm})$, sodium $(2540 \pm 4.67 \mathrm{ppm})$, iron $(58.57 \pm 0.97 \mathrm{ppm})$, Zinc $(0.02 \pm 0.00 \mathrm{ppm})$, potassium $(0.38 \pm 0.09 \mathrm{ppm})$, manganese $(2.08 \pm 0.23 \mathrm{ppm})$, calcium $(685 \pm 1.76 \mathrm{ppm})$, nickel $(0.14 \pm 0.08 \mathrm{ppm})$, copper $(1.10 \pm 0.00 \mathrm{ppm})$ and magnesium $(1360 \pm$ $2.07 \mathrm{ppm})$, while that of the extract detected selenium $(0.31 \pm 0.01 \mathrm{ppm})$, sodium $(5.12 \pm 0.53 \mathrm{ppm})$, iron $(0.84 \pm 0.37$ $\mathrm{ppm})$, Zinc $(2.37 \pm 0.72 \mathrm{ppm})$, potassium $(0.40 \pm 0.05 \mathrm{ppm})$, manganese $(1.04 \pm 0.05 \mathrm{ppm})$, calcium $(2.31 \pm 0.13 \mathrm{ppm})$, nickel $(0.07 \pm 0.50 \mathrm{ppm})$, copper $(0.60 \pm 0.01 \mathrm{ppm})$, chromium $(0.04 \pm 0.00 \mathrm{ppm})$, cobalt $(0.13 \pm 0.01 \mathrm{ppm})$, lead $(0.10 \pm$ $0.05 \mathrm{ppm})$ and magnesium $(5.12 \pm 0.53 \mathrm{ppm})$.

\subsection{Qualitative and Quantitative Phytochemical Constituents of the Dried Stem Bark, Extract and Fractions}

Qualitative phytochemical tests on the stem bark gave positive reactions for alkaloids, flavones, glycosides, phenol, resins, saponins, terpenoids, carbohydrates, and amino acids. The extract tested positive to alkaloids, flavones, glycosides, phenols, resins, saponins, terpenoids, and carbohydrates. Ethylacetate fraction gave positive reactions for alkaloids, flavones, glycosides, phenols, resins, and terpenoids. The n-hexane fraction tested positive to flavones, glycosides, resins, and terpenoids. Dichloromethane fraction tested positive to the resin. Methanol fraction gave positive reactions for alkaloid, flavones, glycosides, phenol, and terpenoid (Table 1). Qualitative phytochemical screening of CA1 gave a positive reaction for terpenoid. The quantitative phytochemical compositions of stem bark were alkaloids (57.34 $\mathrm{mg} / 100 \mathrm{~g})$, saponin $(06.94 \mathrm{mg} / 100 \mathrm{~g})$, glycosides $\left(2.019 \times 10^{-3} \mathrm{mg} / 100 \mathrm{~g}\right)$, phenol $(02.31 \mathrm{mg} / 100 \mathrm{~g})$ and flavones $(0.92$ $\mathrm{mg} / 100 \mathrm{~g})$. The phytochemical compositions of extract were alkaloids $(51.98 \mathrm{mg} / 100 \mathrm{~g})$, saponin $(01.03 \mathrm{mg} / 100 \mathrm{~g})$, glycosides $\left(1.897 \times 10^{-3} \mathrm{mg} / 100 \mathrm{~g}\right)$, phenol $(07.12 \mathrm{mg} / 100 \mathrm{~g})$ and flavones $(05.50 \mathrm{mg} / 100 \mathrm{~g})$, while that of $\mathrm{HF}$, EF and MF were (glycosides $(0.063 \mathrm{mg} / 100 \mathrm{~g})$ and flavones $(25.27 \mathrm{mg} / 100 \mathrm{~g})$ ), (alkaloid $(41.16 \mathrm{mg} / 100 \mathrm{~g})$, glycosides $(0.200 \mathrm{mg} / 100$ $\mathrm{g})$, phenol $(05.56 \mathrm{mg} / 100 \mathrm{~g})$, and flavones $(26.72 \mathrm{mg} / 100 \mathrm{~g})$ ) and (alkaloid $(80.02 \mathrm{mg} / 100 \mathrm{~g})$, glycosides $(0.170 \mathrm{mg} / 100$ g), phenol (26.53 mg/100 g), and flavones (33.19 mg/100 g)) respectively (Table 2).

\subsection{Acute Toxicity Studies}

Oral administration of the extract to rats caused no death at doses ranging from $2000-5000 \mathrm{mg} / \mathrm{kg}$ body weight. This indicates that the extract is safe.

\subsection{Effect of Extract, Fractions, and CA1 on Systemic Acute Edema}

The dichloromethane/methanol extract caused significant $(\mathrm{p}<0.05)$ inhibition of systemic acute edema. Intraperitoneal administration of the extract significantly $(\mathrm{p}<0.05)$ inhibited acute edema within $0.5-3.5 \mathrm{~h}$. Increases in mean paw volume were significantly $(\mathrm{p}<0.05)$ inhibited by ethyl acetate, $\mathrm{n}$-hexane and methanol fractions within $1-3,1.5$ and 3, and $1.5 \mathrm{~h}$ respectively. Ethyl acetate fraction (EF) caused consistent and profound inhibition of edema than $\mathrm{n}-$ hexane and methanol fractions (Tables 4, 5, and 7). CA1 at a low dose of $10 \mathrm{mg} / \mathrm{kg}$ exhibited significant $(\mathrm{p}<0.05)$ inhibition of systemic acute edema confirming it as the bioactive phytochemical constituent of $C$. adansonii with anti-inflammatory activity.

\subsection{Effect of Fractions on Hypotonicity-Induced Hemolysis}

The fractions caused significant $(\mathrm{p}<0.05)$ concentration-related inhibition of hypotonicity-induced hemolysis of red blood cells. The greatest inhibition was afforded by the highest dose of ethyl acetate fraction. Table 11 shows that at the highest dose, the percentage inhibition of hemolysis of the various fractions were found to decrease in this order: ethyl acetate fraction $>$ dichloromethane fraction $>$ n-hexane fraction $>$ Diclofenac $>$ methanol fraction.

\subsection{Effect of Extract on Chronic Formaldehyde-induced Arthritis}

Daily intraperitoneal administration of the extract significantly $(\mathrm{p}<0.05)$ suppressed both the early and late stages of the development of formaldehyde arthritis in a non-dose-related manner. The lower dose $(200 \mathrm{mg} / \mathrm{kg})$ significantly $(\mathrm{p}<0.05)$ exhibited the highest inhibitions which are also significant $(\mathrm{p}<0.05)$ when compared with both aspirin $(100$ $\mathrm{mg} / \mathrm{kg}$ ) and dexamethasone $(1 \mathrm{mg} / \mathrm{kg})$. This actually reduces the global edematous response due to arthritis. The global edematous response to formaldehyde arthritis quantified as the area under the curve (AUC) of the time-course of the arthritis event shows that $(200 \mathrm{mg} / \mathrm{kg})$ exhibited the highest percentage inhibition of 46.695 , while $500 \mathrm{mg} / \mathrm{kg}$ had percentage inhibition of $28.51 \%$ (Fig. 1). Increases in mean paw volume were significantly $(\mathrm{p}<0.05)$ inhibited by 500 $\mathrm{mg} / \mathrm{kg}$ of extract at days 1, 2, 6, 7 and 8 (Table 6).

\subsection{Effect of Extract on Haematological Indices in arthritis}

Chronic intraperitoneal administration of extract caused different effects on the levels of hematological parameters assayed in relation to the baseline values (Tables 8 and 9). The extract at varying concentrations caused significant $(\mathrm{p}<0.05)$ decrease in neutrophil counts. Conversely, WBC and lymphocyte counts were significantly $(\mathrm{P}<0.05)$ increased. The extract caused a slight decrease in the $\mathrm{Hb}$ and PCV levels as well as a moderate increase in the platelet counts. 


\subsection{Effect of extract on Serum Electrolytes}

Chronic intraperitoneal administration of dichloromethane/methanol extract caused different effects on serum electrolyte concentrations of treated animals (Table 10). The extract caused significant $(\mathrm{P}<0.05)$ increase in serum selenium and copper concentrations. The extract also caused moderate decrease in serum concentration of zinc. Dexamethazone caused a significant $(\mathrm{P}<0.05)$ decrease in serum selenium concentration and increase in serum copper concentration.

\subsection{Effects of Extract on Serum Total Protein Concentration}

Sub-chronic intraperitoneal administration of extract caused a mild increase in the serum total protein concentration of treated rats in relation to baseline values (Table 12).

\subsection{Effects of Extract on Serum Uric Acid Concentration}

Sub-chronic intraperitoneal administration of extract caused an increase on the serum uric acid levels of treated rats in relation to baseline value but caused significant $(\mathrm{p}<0.05)$ increase in serum uric acid level at the dose of $500 \mathrm{mg} / \mathrm{kg}$ in relation to untreated control group (3\% Tween 80$)$ (Table 13).

\section{Discussion}

Anti-inflammatory activity-guided studies technique, using egg-albumin induced rat hind paw edema method of Winter et al., (1962) as an activity guide, was employed in this study to relate the anti-inflammatory activity of C. adansonii stem bark extract to its phytochemical constituents (Winter et al., 1962). This was to narrow down the anti-inflammatory effect to specific phytochemical constituent for subsequent isolation, identification and confirmation as the antiinflammatory phytochemical constituent of the stem bark of this plant. Thus, sequential separation of constituents of the dichloromethane/methanol stem bark extract, following the anti-inflammatory effect, yielded several solvent fractions. Further separation of the fraction with the highest activity afforded one anti-inflammatory compound CA1 (a terpenoid). Preliminary assessment of acute toxicity of the extract in rats using the oral route revealed an $\mathrm{LD}_{50}$ value greater than 5 $\mathrm{g} / \mathrm{kg}$ suggesting the extract may be generally regarded as safe. This substantiates the fact that triterpenes are naturally occurring bioactive agents in fruits and vegetables has the knack to interfere with multiple cell-signaling pathways. These bioactive agents can be used either in their natural forms for prevention or perhaps in their pure form for therapy, where low dose may be desired. The observed effects on systemic acute edema indicates that increase in mean paw volumes for groups treated with extract, $\mathrm{n}$-hexane fraction, ethyl acetate fraction, methanol fraction and CA1 were significantly suppressed at (0.5-4.0), (1.5 and 3.0), (1.0-3.0), (1.5) and (0.5-3.5) hours respectively. These observations could be explained from the correlations between the therapeutic inhibition pattern (suppression of the mean paw volumes), the percentage extractive yields of these fractions (in the decreasing order of ethyl acetate (EF), n-hexane (n-HF), methanol (MF) and dichloromethane (DF) fractions) and the qualitative phytochemical screening of the fractions, extract and CA1 which indicates the presence of terpenoids at varied degrees. The reason for the high plasma concentration of the active constituent of the extract following intraperitoneal administration is due to the physicochemical nature of the bioactive compound CA1 which is a white solid crystal that is highly insoluble in water, but soluble in acetone and chloroform. The lipid-water partition coefficient is among the major factors that control the rate of drug absorption (Nanjwade, Patel, Udhani, \& Manvi, 2011). The lipophilic nature of CA1 has a major role to play in its absorption and distribution after intraperitoneal administration as it can easily traverse the membrane by dissolving in the lipid bilayers. Anemia of any type affects the results of one or more of these hematological parameters: hematocrit (PCV), hemoglobin and red blood cell count. The extract at varying concentrations could not alter the decrease in the hemoglobin and PCV levels caused by formaldehyde-induced arthritis. However, formaldehyde-induced arthritis shows that the extract exhibited a nonsignificant increase in serum copper concentrations at low dose, but a significant increase at high dose. Copper-containing ferroxidase (ceruloplasmin) transports iron across the cell membrane (Ramos et al., 2016). Moreover copper is an integral part of ALA-synthase a key enzyme in heme synthesis, which indicates that decrease or deficiency of serum copper will manifest as anemia, decrease in erythropoiesis. This is to say that the observed non-significant decreases in hemoglobin and pack cell volume in this present research have nothing to do with the oxidation of ferrous ion to ferric form by ferroxidase and the synthesis of heme by ALA-synthase. However, our observations agree with Agayet al. 2005 and Banhget al. 2000, who reported increase in serum copper levels from the first day of burn injury to the tenth day (Agay et al., 2005; Bang, Mattappallil, Dashti, \& Al-Bader, 2000). The contributive roles of these trace elements ( $\mathrm{Zn}, \mathrm{Mn}$ and $\mathrm{Cu}$ ) in both oxidative and inflammatory processes indicate why their body distribution profile changes following burn injury (Rehou, Shahrokhi, Natanson, Stanojcic, \& Jeschke, 2018). Increase in oxidative stress in burn injury triggers mobilization of these trace elements $(\mathrm{Zn}, \mathrm{Mn}$ and $\mathrm{Cu}$ ) to the liver for the biosynthesis of antioxidant enzyme $\mathrm{Cu} / \mathrm{Zn}$-superoxide dismutase (SOD) (Rehou et al., 2018). In order to prevent the escalation of oxidative injury and to limit the diffusion of reactive oxidative species released by injured tissues there is always an observed increase in the liver $\mathrm{Cu} / \mathrm{Zn}$ SOD activities within 6 hours to 4 days after burn injury. This may have accounted for the non-significant changes in serum $\mathrm{Zn}$ and $\mathrm{Cu}$ concentrations in the extract-treated group. However, our observed significant and mild increases in serum Cu level could be attributed to net gain between intestinal absorption and excretion of copper, copper released from other tissues of the organism, hemolysis of red cells, from the copper rich extract or increase in ceruloplasmin (ferroxidase) synthesis, an acute-phase protein that plays a critical role in inflammation. If we had observed a decrease in the bone density in both treated and untreated formaldehyde-induced arthritis groups, we could have raised the hypothesis of mobilization of $\mathrm{Cu}$ from the bone. The extract at varying concentrations used exhibited non-significant decrease in serum zinc concentration on day-10 compared with both the untreated control group and baseline. These observations agree with those of Agayet al. 
2005 and Khorasani, 2012, who reported that the concentration of serum zinc, declined within six to seventh two hours of burn injury before it returns to near control levels (Agay et al., 2005; Khorasani, Hosseinimehr, \& Kaghazi, 2008). There exist correlation between reduction in serum Zn concentration and its hepatic accumulation (Bang et al., 2000; Mohommad, Zhou, Cave, Barve, \& McClain, 2012). Nevertheless, increased (Hansson, Huunan-Seppala, \& Mattila, 1975) or unchanged (Aaseth, Munthe, Forre, \& Steinnes, 1978; Mataran Perez et al., 1989) serum zinc levels have also been observed. The correlation between serum decrease and hepatocyte increase signifies that this hepatic increase occurs at serum depletion cost (Zoli et al., 1998). Serum albumin an important Zn-carrier is decreased during inflammation and this presents positive correlation with the reduced serum zinc levels (Milanino, Marrella, Gasperini, Pasqualicchio, \& Velo, 1993). Our observation shows that the mean serum selenium of the group treated with high dose of extract did not increase significantly, but the low dose exhibited a significant increase in serum selenium on day-10 in comparison with the baseline. Hypothetically, the main factors responsible for decreased serum selenium concentration during systematic inflammatory response are; redistribution of selenium from the circulation to tissues that are involved in immune function (Ashton et al., 2009; Iglesias, Leite, Paes, Oliveira, \& Sarni, 2014), increase in vascular permeability due to endothelial injury that favors trans-capillary escape of selenium transporter proteins (Vincent \& Forceville, 2008), down-regulation of essential genes required for selenium metabolism as part of the acute-phase response and impair regular selenoprotein $\mathrm{P}$ biosynthesis by hepatocytes (Renko et al., 2009). In this study, we report an increase in concentration of serum selenium for groups treated with varied concentrations of extract only, which most results in literature could not explain. There are three possible explanations for this observed increase in selenium. First, the extract may have activated the biosynthesis of selenoprotein $\mathrm{P}$, by up-regulating the gene that is essential for selenium metabolism in acute-phase response. Secondly, the extract may have decreased or inhibited vascular permeability, which is a hallmark of inflammation, thereby halting the trans-capillary escape of selenium transporter proteins. Thirdly, electrolytes analyses of the stem bark and extract indicate the presence of selenium with concentrations of $01.30 \pm 0.05$ and $0.31 \pm 0.25$ ppm respectively. The observed significant changes in WBCT count and lymphocytes suggest that the acquired immune response of the body has been compromised by the formaldehyde induced arthritis but could not be significantly suppressed by the extract at the tested doses. The extract may have decreased neutrophil egress directly by inhibiting the interaction between chemokine receptor 2 (CXCR2) and its ligands or indirectly by antagonizing the action of granulocyte colony stimulating factor (G$\mathrm{CSF}$ ). Formaldehyde induced-arthritis was significantly inhibited by the extract at varying concentrations with the highest percentage inhibition occurring between 7-10 days. Injection of formaldehyde into the hind paw induces a biphasic pain response; the first phase results from direct activation of primary afferent sensory neurons, through a specific and direct action on Transient Receptor Potential A1 (TRPA1), a member of the Transient Receptor Potential family of cation channels that are highly expressed by a subset of c-fiber nociceptors (Nagata, Duggan, Kumar, \& Garcia-Anoveros, 2005).

\section{Conclusion}

Phytochemical and biological-activity-guided anti-inflammatory studies on the dichloromethane/methanol extract of $C$. adansonii stem bark were conducted to find the phytochemical (biomolecule) exhibiting the antiinflammatory activities. Sub-fractionation of ethyl acetate fraction gave an anti-inflammatory bioactive compound CA1 identified as triterpene.

\section{Conflict of Interest}

All authors state that there is no conflict of interest.

\section{Acknowledgment}

This work was sponsored by the Brain-Phosphorylationship Scientific Solution Services. 5 ${ }^{\text {th }}$ Floor, Right Wing, No. 9 Ogui Road Enugu, Enugu State. Nigeria. We thank the staff of Brain-PS ${ }^{3}$ for their contributions.

\section{Author Contributions}

E.M.O., N.O.U. and O.C.O. conceived and designed the study. E.M.O and O.C.O conducted the experiments and data analysis under the supervision of N.O.U. The manuscript was drafted by E.M.O., N.O.U. and O.C.O.

\section{References}

i. Aaseth, J., Munthe, E., Forre, O., \& Steinnes, E. (1978). Trace elements in serum and urine of patients with rheumatoid arthritis. Scand J Rheumatol, 7(4), 237-240. doi:10.3109/03009747809095662

ii. Agay, D., Anderson, R. A., Sandre, C., Bryden, N. A., Alonso, A., Roussel, A. M., \& Chancerelle, Y. (2005). Alterations of antioxidant trace elements $(\mathrm{Zn}, \mathrm{Se}, \mathrm{Cu})$ and related metallo-enzymes in plasma and tissues following burn injury in rats. Burns, 31(3), 366-371. doi:10.1016/j.burns.2004.11.010

iii. Ashton, K., Hooper, L., Harvey, L. J., Hurst, R., Casgrain, A., \& Fairweather-Tait, S. J. (2009). Methods of assessment of selenium status in humans: a systematic review. Am J Clin Nutr, 89(6), 2025S-2039S. doi:10.3945/ajcn.2009.27230F

iv. Bang, R. L., Mattappallil, A. B., Dashti, H. M., \& Al-Bader, A. A. (2000). Thermal injury and changes in the trace elements. Journal of Trace Elements in Experimental Medicine, 13(3), 255-264. doi:Doi 10.1002/1520670x(2000)13:3<255::Aid-Jtra2>3.0.Co;2-J

v. Charles A Janeway, Paul Travers, Mark Walport, and Mark J Shlomchik. Immunology: The Immune System in Health and Disease. 5th edition 2001. New York: Garland Science; 2001.ISBN-10: 0-8153-3642-X 
vi. Chen, L., Deng, H., Cui, H., Fang, J., Zuo, Z., Deng, J., . . . Zhao, L. (2018). Inflammatory responses and inflammation-associated diseases in organs. Oncotarget, 9(6), 7204-7218. doi:10.18632/oncotarget.23208

vii. Chinnasamy, V., Subramaniyan, V., Chandiran, S., Kayarohanam, S., Kanniyan, D. C., Velaga, V., \& Muhammad, S. (2019). Antiarthritic Activity of Achyranthes Aspera on Formaldehyde - Induced Arthritis in Rats. Open Access Maced J Med Sci, 7(17), 2709-2714. doi:10.3889/oamjms.2019.559

viii. Galley, H. F., \& Webster, N. R. (2004). Physiology of the endothelium. Br J Anaesth, 93(1), 105-113. doi:10.1093/bja/aeh163

ix. Gieling, R. G., Rajasekaran, V., Jurk, D., Elsharkawy, A. M., Burt, A. D., Oakley, F., \& Mann, D. A. (2009). The AntiInflammatory and Anti-Proliferative Properties of the Nfkb1 (P50) Gene Protect against Hepatocellular Carcinoma. Hepatology, 50(4), 881a-881a.

x. Gonzalez-Muniesa, P., Garcia-Gerique, L., Quintero, P., Arriaza, S., Lopez-Pascual, A., \& Martinez, J. A. (2015). Effects of Hyperoxia on Oxygen-Related Inflammation with a Focus on Obesity. Oxid Med Cell Longev, 2015, 8957827. doi:10.1155/2016/8957827

xi. Hansson, L., Huunan-Seppala, A., \& Mattila, A. (1975). The content of calcium, magnesium, copper, zinc, lead and chromium in the blood of patients with rheumatoid arthritis. Scand J Rheumatol, 4(1), 33-38.

xii. Harborne, J. B. (1998). Tony Swain and phytochemical methods. Phytochemistry, 49(5), 1163-1164.

xiii. Iglesias, S. B., Leite, H. P., Paes, A. T., Oliveira, S. V., \& Sarni, R. O. (2014). Low plasma selenium concentrations in critically ill children: the interaction effect between inflammation and selenium deficiency. Crit Care, 18(3), R101. doi:10.1186/cc13877

xiv. Igoli, N. P., Clements, C. J., Singla, R. K., Igoli, J. O., Uche, N., \& Gray, A. I. (2014). Antitrypanosomal Activity \& Docking Studies of Components of Crateva adansonii DC Leaves: Novel Multifunctional Scaffolds. Current Topics in Medicinal Chemistry, 14(8), 981-990. doi:Doi 10.2174/1568026614666140324120006

xv. Jang, Y., Kim, M., \& Hwang, S. W. (2020). Molecular mechanisms underlying the actions of arachidonic acidderived prostaglandins on peripheral nociception. J Neuroinflammation, 17(1), 30. doi:10.1186/s12974-0201703-1

xvi. Kanase, R., Patil, S., \& Kanase, A. (1994). Effect of hepatoprotective ayurvedic drugs on lysosomal enzymes during hepatic injury induced by single dose of CCl4. Indian J Exp Biol, 32(5), 328-332.

xvii. Khorasani, G., Hosseinimehr, S. J., \& Kaghazi, Z. (2008). The alteration of plasma's zinc and copper levels in patients with burn injuries and the relationship to the time after burn injuries. Singapore Med J, 49(8), 627630.

xviii. Maroon-Lango, C. J., Schneider, K. L., Turner, R. S., Presting, G. G., \& Alvarez, A. M. (2010). Xanthomonas sacchari - a pathogen or an endophyte? Phytopathology, 100(6), S78-S78.

xix. Mataran Perez, L., Gonzalez Dominguez, J., Rodriguez Perez, M., Rodrigo, D., Abellan Perez, M., \& Salvatierra Rios, D. (1989). [Plasma and intraerythrocytic zinc in rheumatoid arthritis and ankylosing spondylitis]. An Med Interna, 6(12), 629-632.

xx. Milanino, R., Marrella, M., Gasperini, R., Pasqualicchio, M., \& Velo, G. (1993). Copper and zinc body levels in inflammation: an overview of the data obtained from animal and human studies. Agents Actions, 39(3-4), 195209. doi:10.1007/bf01998974

xxi. Mohommad, M. K., Zhou, Z. X., Cave, M., Barve, A., \& McClain, C. J. (2012). Zinc and Liver Disease. Nutrition in Clinical Practice, 27(1), 8-20. doi:10.1177/0884533611433534

xxii. Nagata, K., Duggan, A., Kumar, G., \& Garcia-Anoveros, J. (2005). Nociceptor and hair cell transducer properties of TRPA1, a channel for pain and hearing. J Neurosci, 25(16), 4052-4061. doi:10.1523/JNEUROSCI.001305.2005

xxiii. Nanjwade, B. K., Patel, D. J., Udhani, R. A., \& Manvi, F. V. (2011). Functions of lipids for enhancement of oral bioavailability of poorly water-soluble drugs. Sci Pharm, 79(4), 705-727. doi:10.3797/scipharm.1105-09

xxiv. Ogbole, O. O., \& Ajaiyeoba, E. O. (2010). Traditional Management of Tuberculosis in Ogun State of Nigeria: The Practice and Ethnobotanical Survey. African Journal of Traditional Complementary and Alternative Medicines, 7(1), 79-84.

xxv. Perez, R. M. (1996). Anti-inflammatory activity of Ambrosia artemisiaefolia and Rhoeo spathacea. Phytomedicine, 3(2), 163-167. doi:Doi 10.1016/S0944-7113(96)80030-4

xxvi. Ramos, D., Mar, D., Ishida, M., Vargas, R., Gaite, M., Montgomery, A., \& Linder, M. C. (2016). Mechanism of Copper Uptake from Blood Plasma Ceruloplasmin by Mammalian Cells. Plos One, 11(3), e0149516. doi:10.1371/journal.pone.0149516

xxvii. Rehou, S., Shahrokhi, S., Natanson, R., Stanojcic, M., \& Jeschke, M. G. (2018). Antioxidant and Trace Element Supplementation Reduce the Inflammatory Response in Critically Ill Burn Patients. J Burn Care Res, 39(1), 1-9. doi:10.1097/BCR.0000000000000607

xxviii. Renko, K., Hofmann, P. J., Stoedter, M., Hollenbach, B., Behrends, T., Kohrle, J., Schomburg, L. (2009). Downregulation of the hepatic selenoprotein biosynthesis machinery impairs selenium metabolism during the acute phase response in mice. FASEB J, 23(6), 1758-1765. doi:10.1096/fj.08-119370

xxix. Ricciotti, E., \& FitzGerald, G. A. (2011). Prostaglandins and Inflammation. Arteriosclerosis Thrombosis and Vascular Biology, 31(5), 986-1000. doi:10.1161/Atvbaha.110.207449

xxx. Ritchie, R. H., Drummond, G. R., Sobey, C. G., De Silva, T. M., \& Kemp-Harper, B. K. (2017). The opposing roles of NO and oxidative stress in cardiovascular disease. Pharmacological Research, 116, 57-69. doi:10.1016/j.phrs.2016.12.017 
xxxi. Shinde, U. A., Phadke, A. S., Nair, A. M., Mungantiwar, A. A., Dikshit, V. J., \& Saraf, M. N. (1999). Studies on the anti-inflammatory and analgesic activity of Cedrus deodara (Roxb.) Loud. wood oil. Journal of Ethnopharmacology, 65(1), 21-27. doi:Doi 10.1016/S0378-8741(98)00150-0

xxxii. Siddiqui, A. A., \& Khan, S. A. (1997). Alkaloidal content of genus Fumaria. Asian Journal of Chemistry, 9(4), 579582.

xxxiii. Takasugi, N. (1993). Calcium-induced vasodilation due to increase in nitric oxide formation in the vascular bed of rabbit ear preparation. Jpn J Pharmacol, 61(3), 177-182. doi:10.1254/jjp.61.177

xxxiv. Trease, G.E. and Evans, W.C. (1983) Textbook of pharmacognosy. 12th Edition, Tindall and Co., London, 343383.

xxxv. Udeh, N. E., \& Onoja, S. O. (2015). Analgesic and free radical scavenging activities of hydromethanolic extract of Crateva adansonii stem bark. J Intercult Ethnopharmacol, 4(3), 224-227. doi:10.5455/jice.20150403055054

xxxvi. Vincent, J. L., \& Forceville, X. (2008). Critically elucidating the role of selenium. Curr Opin Anaesthesiol, 21(2), 148-154. doi:10.1097/AC0.0b013e3282f49afe

xxxvii. Winter, C. A., Risley, E. A., \& Nuss, G. W. (1962). Carrageenin-induced edema in hind paw of the rat as an assay for antiiflammatory drugs. Proc Soc Exp Biol Med, 111, 544-547. doi:10.3181/00379727-111-27849

xxxviii. Zoli, A., Altomonte, L., Caricchio, R., Galossi, A., Mirone, L., Ruffini, M. P., \& Magaro, M. (1998). Serum zinc and copper in active rheumatoid arthritis: Correlation with interleukin 1 beta and tumour necrosis factor alpha. Clinical Rheumatology, 17(5), 378-382. doi:Doi 10.1007/Bf01450895

\begin{tabular}{|c|c|c|c|c|c|c|c|}
\hline \multirow{2}{*}{$\begin{array}{c}\text { Phytochemical } \\
\text { Constituents }\end{array}$} & \multicolumn{9}{|c|}{ Relative Presence } \\
\cline { 2 - 7 } & $\begin{array}{c}\text { Stem Bark } \\
\text { Powder }\end{array}$ & DCMME & EF & HF & DCMF & MF & CA1 \\
\hline Alkaloid & +++ & ++ & ++ & ND & ND & +++ & ND \\
\hline Amino acids & +++ & ND & ND & ND & ND & ND & ND \\
\hline Aromatic amino acids & +++ & ND & ND & ND & ND & ND & ND \\
\hline Carbohydrate & +++ & +++ & ND & ND & ND & ND & ND \\
\hline Flavones & + & ++ & +++ & +++ & ND & +++ & ND \\
\hline Flavonoid & + & ND & ND & ND & ND & ND & ND \\
\hline Glycosides & ++ & +++ & +++ & ++ & ND & +++ & ND \\
\hline Phenol & + & + & ++ & ND & ND & +++ & ND \\
\hline Reducing Sugar & ND & ++ & ND & ND & ND & ND & ND \\
\hline Resin & ++ & +++ & +++ & +++ & +++ & ND & ND \\
\hline Saponins & ++ & ++ & ND & ND & ND & ND & ND \\
\hline Steroid & ND & ND & ND & ND & ND & ND & ND \\
\hline Tannins & ND & ND & ND & ND & ND & ND & ND \\
\hline Terpenoid & +++ & +++ & +++ & +++ & ND & +++ & +++ \\
\hline Oil & ND & ND & ND & ND & ND & ND & ND \\
\hline
\end{tabular}

Table 1: Phytochemical constituents of stem bark, extract, fractions and CA1

$D C M M E=$ dichloromethane-methanol extract; $E F=$ ethylacetate fraction; $H F=n$-hexane fraction; $M F=$ methanol fraction; $D C M F=$ dichloromethane fraction; $C A 1=$ isolated compound; Key: + = Present in low quantity; ++ = Present in moderate quantity; $+++=$ Present in large quantity; $N D=$ Not Detected

\begin{tabular}{|c|c|c|c|c|c|}
\hline \multirow{2}{*}{ Samples } & \multicolumn{5}{|c|}{ Phytochemical Constituent (mg/100 g) } \\
\cline { 2 - 6 } & Alkaloids & Saponins & $\begin{array}{c}\text { Glycosides } \\
\left(\mathbf{1 0}^{-3} \mathbf{)}\right.\end{array}$ & Phenols & Flavones \\
\hline Stem Bark & 57.34 & 06.94 & 2.019 & 02.31 & 00.92 \\
\hline Extract & 51.98 & 01.03 & 1.897 & 07.12 & 05.50 \\
\hline HF & Nil & Nil & 0.063 & Nil & 25.27 \\
\hline EF & 41.16 & Nil & 0.200 & 05.56 & 26.72 \\
\hline MF & 80.02 & Nil & 0.170 & 26.53 & 33.19 \\
\hline
\end{tabular}

Table 2: Quantitative Phytochemical Constituents of Stem Bark, Extract, and Fractions $H F=N$-Hexane Fraction; $E F=$ Ethyl-Acetate Fraction; $M F=$ Methanol Fraction 


\begin{tabular}{|c|c|c|}
\hline \multirow{2}{*}{ Element } & \multicolumn{2}{|c|}{ Concentration (ppm) } \\
\cline { 2 - 3 } & Stem Bark & Extract \\
\hline Sodium & $2540.00 \pm 4.67$ & $5.12 \pm 0.53$ \\
\hline Copper & $1.10 \pm 0.00$ & $0.60 \pm 0.01$ \\
\hline Manganese & $2.08 \pm 0.23$ & $1.04 \pm 0.05$ \\
\hline Magnesium & $1360.00 \pm 2.07$ & $5.12 \pm 0.53$ \\
\hline Selenium & $1.30 \pm 0.05$ & $0.31 \pm 0.25$ \\
\hline Chronium & Nil & $0.04 \pm 0.00$ \\
\hline Colbat & Nil & $0.13 \pm 0.01$ \\
\hline Calcium & $685.00 \pm 1.76$ & $2.31 \pm 0.13$ \\
\hline Nickel & $0.14 \pm 0.08$ & $0.07 \pm 0.50$ \\
\hline Zinc & $0.02 \pm 0.00$ & $2.37 \pm 0.72$ \\
\hline Lead & Nil & $0.10 \pm 0.05$ \\
\hline Iron & $58.57 \pm 0.97$ & $0.84 \pm 0.37$ \\
\hline Potassium & $0.38 \pm 0.09$ & $0.40 \pm 0.41$ \\
\hline
\end{tabular}

Table 3: Mineral Composition of Stem Bark and Extract

\begin{tabular}{|c|c|c|c|c|c|c|c|c|c|}
\hline \multirow[t]{2}{*}{ Treatment } & \multirow{2}{*}{$\begin{array}{c}\text { Dose } \\
(\mathrm{mg} / \mathrm{kg})\end{array}$} & \multicolumn{8}{|c|}{ Edema (ml) } \\
\hline & & $0.5 \mathrm{~h}$ & $1 \mathrm{~h}$ & $1.5 \mathrm{~h}$ & $2 \mathrm{~h}$ & $2.5 \mathrm{~h}$ & $3 \mathrm{~h}$ & $3.5 \mathrm{~h}$ & $4 \mathrm{~h}$ \\
\hline Extract & 옹 & 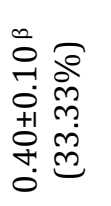 & 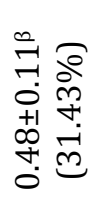 & $\begin{array}{ll}0 & 0 \\
0 & 0 \\
0 & 0 \\
+1 & 0 \\
0 & 0 \\
0 & 0 \\
0 & =\end{array}$ & 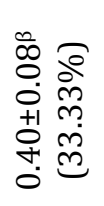 & 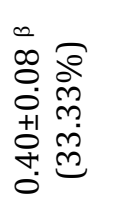 & 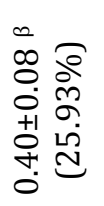 & 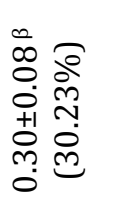 & 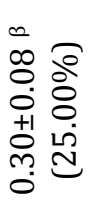 \\
\hline Control & ' & $\begin{array}{l}+ \\
\stackrel{+}{0} \\
+1 \\
0 \\
0 \\
0\end{array}$ & $\begin{array}{l}\infty \\
0 \\
0 \\
+1 \\
0 \\
0 \\
0\end{array}$ & $\begin{array}{l}\infty \\
0 \\
0 \\
+1 \\
0 \\
0 \\
0 \\
0\end{array}$ & $\begin{array}{l}\infty \\
0 \\
0 \\
+ \\
+1 \\
0 \\
0 \\
0\end{array}$ & $\begin{array}{l}\infty \\
0 \\
0 \\
+1 \\
+1 \\
0 \\
0\end{array}$ & \begin{tabular}{l} 
Ln \\
0 \\
0 \\
+1 \\
+ \\
\multirow{+}{+}{} \\
0
\end{tabular} & 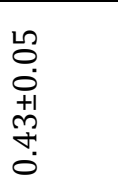 & $\begin{array}{l}\infty \\
0 \\
0 \\
+1 \\
+1 \\
+ \\
\vdots \\
0\end{array}$ \\
\hline
\end{tabular}

Table 4: Effect of Extract on Systemic Acute Edema

Results Are Expressed in Mean \pm SD; $N=4$

The Mean Values with Beta ( $\left.{ }^{B}\right)$ As Superscripts across the Column

Compared with (3\% Tween-80-I.P) Are Considered Significant $(P<0.05)$

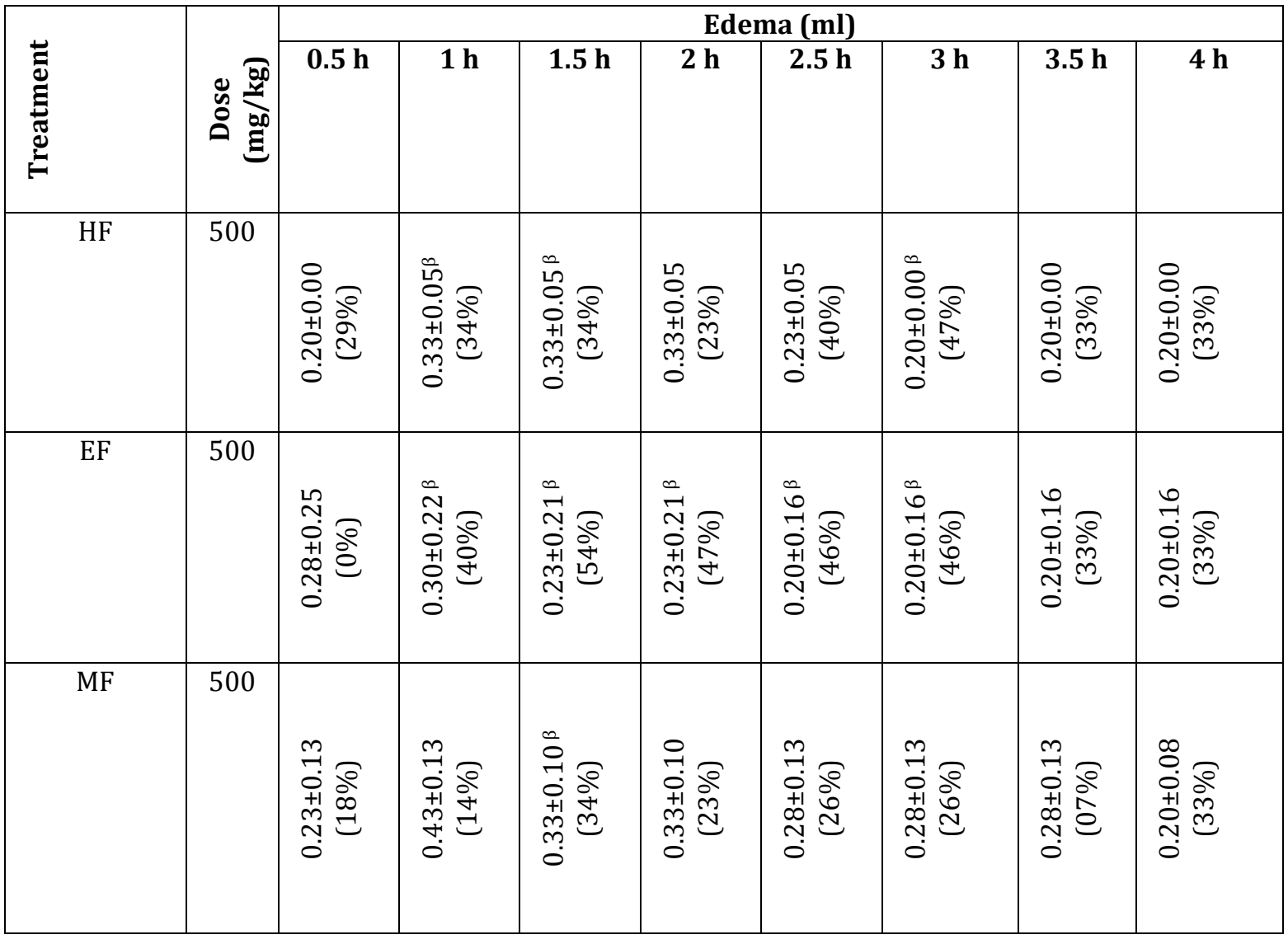




\begin{tabular}{|c|c|c|c|c|c|c|c|c|c|}
\hline \multirow{2}{*}{ 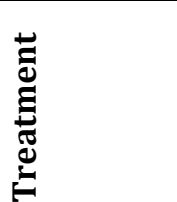 } & \multirow[b]{2}{*}{ 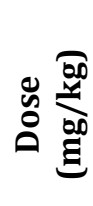 } & \multicolumn{8}{|c|}{ Edema (ml) } \\
\hline & & $0.5 \mathrm{~h}$ & $1 \mathrm{~h}$ & $1.5 \mathrm{~h}$ & $2 \mathrm{~h}$ & $2.5 \mathrm{~h}$ & $3 \mathrm{~h}$ & $3.5 \mathrm{~h}$ & $4 h$ \\
\hline DCMF & 100 & 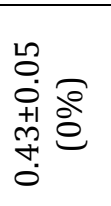 & $\begin{array}{l}0 \\
\stackrel{1}{0} \\
0 \\
+1 \\
0 \\
0 \\
10 \\
0\end{array}$ & $\begin{array}{l}\stackrel{\infty}{+} \\
\stackrel{1}{0} \\
0 \\
+1 \\
0 \\
0 \\
0 \\
0\end{array}$ & 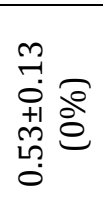 & $\begin{array}{l}\infty \\
0 \\
0 \\
+1 \\
0 \\
0 \\
\text { 유 } \\
0\end{array}$ & $\begin{array}{l}0 \\
\stackrel{1}{0} \\
0 \\
+1 \\
0 \\
+1 \\
+1 \\
0\end{array}$ & \begin{tabular}{l}
0 \\
\multirow{1}{0}{} \\
+1 \\
+1 \\
$\infty$ \\
$m$ \\
0 \\
0
\end{tabular} & $\begin{array}{l}\circ \\
\stackrel{1}{0} \\
\text { +1 } \\
\infty \\
m \\
m \\
0\end{array}$ \\
\hline Ibuprofen & 100 & 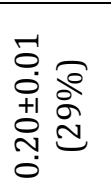 & $\begin{array}{l}8 \\
0 \\
0 \\
+1 \\
0 \\
0 \\
0 \\
0\end{array}$ & 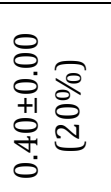 & $\begin{array}{l}8 \\
0 \\
0 \\
+10 \\
+1 \\
\text { †े } \\
0\end{array}$ & 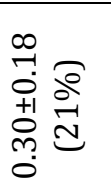 & 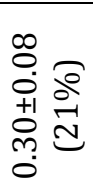 & 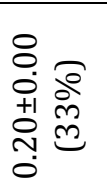 & 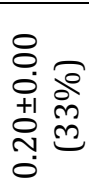 \\
\hline Control & - & $\begin{array}{l}-1 \\
0 \\
+1 \\
+1 \\
\stackrel{1}{1} \\
0 \\
0\end{array}$ & $\begin{array}{l}-1 \\
0 \\
+1 \\
0 \\
\text { Ln } \\
0\end{array}$ & 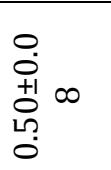 & 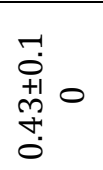 & $\begin{array}{l}-1 \\
0 \\
+1 \\
+1 \\
0 \\
m \\
0\end{array}$ & $\begin{array}{l}-1 \\
\dot{0} \\
+1 \\
\infty \\
m \\
0 \\
0\end{array}$ & $\begin{array}{l}0 \\
\dot{0} \\
+1 \\
+1 \\
m \\
0\end{array}$ & $\begin{array}{l}0 \\
0 \\
+1 \\
+1 \\
0 \\
m \\
0\end{array}$ \\
\hline
\end{tabular}

Table 5: Effect of Fractions on Systemic Acute Edema

$D C M F=$ Dichloromethane fraction, $M F=$ Methanol fraction, $E F=$ Ethylacetate Fraction, $H F=n$-Hexane fraction.

Results are expressed in mean $\pm S D ; n=4$

The mean values with beta $(\beta)$ as superscripts across the column compared with

(3\% Tween-80-I.P) are considered significant $(P<0.05)$

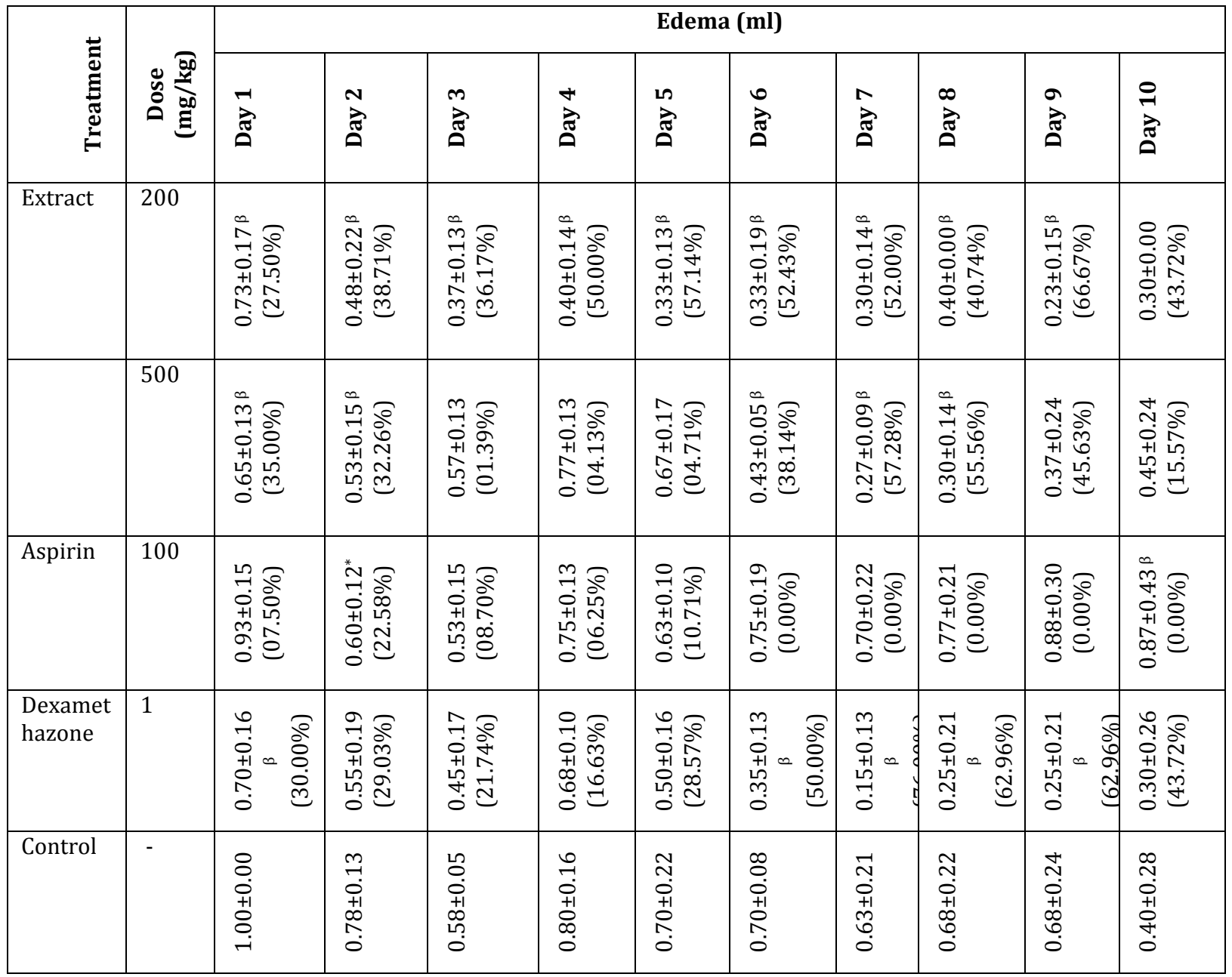

Table 6: Effect of Extract on Chronic Inflammation of the Formaldehyde Arthritis Results Are Expressed in Mean $\pm S D ; N=4$

The Mean Values with Beta (B) As Superscripts across the Column Compared with (3\% Tween-80-I.P.) Are Considered Significant $(P<0.05)$ 


\begin{tabular}{|c|c|c|c|c|c|c|c|c|c|}
\hline \multirow[b]{2}{*}{ Treatment } & \multirow[b]{2}{*}{$\begin{array}{c}\text { Dose } \\
(\mathrm{mg} / \mathrm{kg})\end{array}$} & \multicolumn{8}{|c|}{ Edema (ml) } \\
\hline & & $0.5 \mathrm{~h}$ & $1 \mathrm{~h}$ & $1.5 \mathrm{~h}$ & $2 \mathrm{~h}$ & $2.5 \mathrm{~h}$ & $3 \mathrm{~h}$ & $3.5 \mathrm{~h}$ & $4 \mathrm{~h}$ \\
\hline CA1 & 100 & 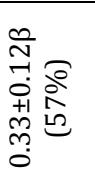 & 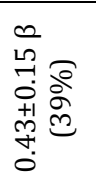 & 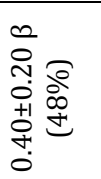 & 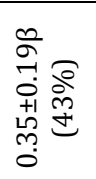 & 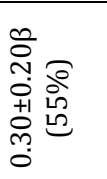 & 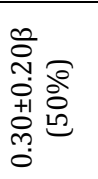 & 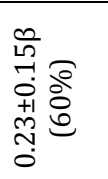 & 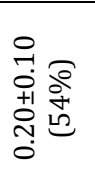 \\
\hline Ibuprofen & 100 & 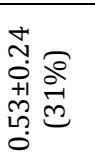 & 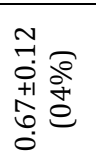 & 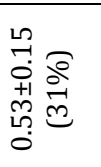 & 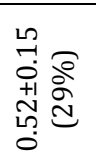 & 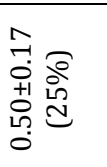 & 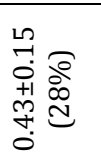 & 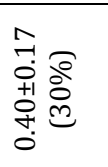 & 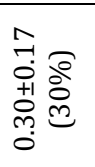 \\
\hline Control & - & \begin{tabular}{l}
\multirow{1}{1}{} \\
$\vdots$ \\
+1 \\
+1 \\
$\hat{0}$ \\
0
\end{tabular} & 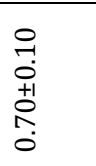 & $\begin{array}{l}0 \\
0 \\
0 \\
+1 \\
\hat{1} \\
0\end{array}$ & $\begin{array}{l}\infty \\
0 \\
0 \\
+1 \\
00 \\
0 \\
0 \\
0\end{array}$ & $\begin{array}{l}0 \\
0 \\
0 \\
+1 \\
\hat{0} \\
0\end{array}$ & $\begin{array}{l}8 \\
0 \\
0 \\
+1 \\
0 \\
0 \\
0\end{array}$ & $\begin{array}{l}0 \\
0 \\
0 \\
+1 \\
10 \\
10 \\
0\end{array}$ & $\begin{array}{l}0 \\
0 \\
0 \\
+1 \\
m \\
+ \\
0\end{array}$ \\
\hline
\end{tabular}

Table 7: Effect of Isolated Compound CA1 on Systemic Acute Edema

Results Are Expressed In Mean \pm SD; $N=4$

The Mean Values with Beta $\left({ }^{B}\right)$ as Superscripts across the Column Compared with

(3\% Tween-80-I.P) Are Considered Significant $(P<0.05)$

\begin{tabular}{|c|c|c|c|c|c|c|c|}
\hline \multirow{2}{*}{ 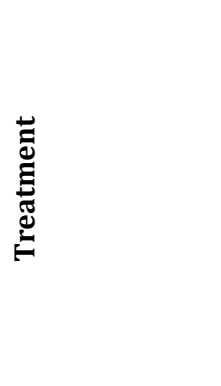 } & \multirow{2}{*}{ 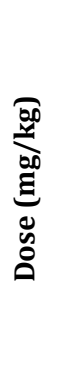 } & \multicolumn{2}{|c|}{ 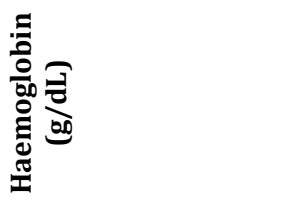 } & \multicolumn{2}{|c|}{ 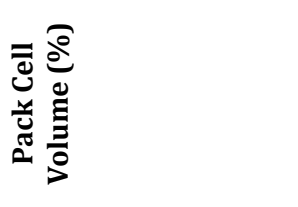 } & \multicolumn{2}{|c|}{ 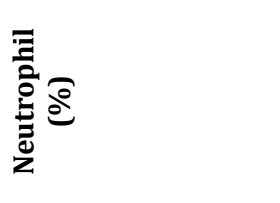 } \\
\hline & & 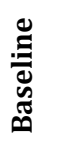 & 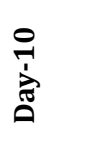 & 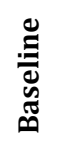 & 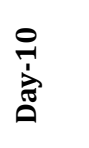 & 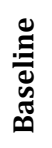 & 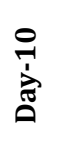 \\
\hline \multirow[t]{2}{*}{ Extract } & $\stackrel{\text { ̊ }}{2}$ & \begin{tabular}{l} 
L \\
0 \\
0 \\
0 \\
+ \\
+1 \\
$\stackrel{1}{N}$ \\
\multirow{N}{*}{} \\
$\infty$
\end{tabular} & 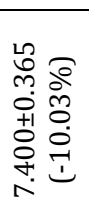 & 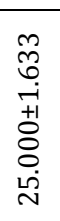 & 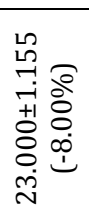 & 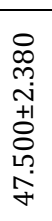 & 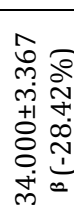 \\
\hline & 号 & 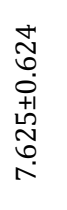 & 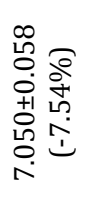 & 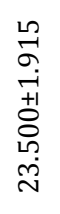 & 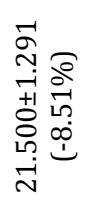 & $\begin{array}{l}\hat{a} \\
\text { o. } \\
+ \\
+1 \\
\dot{0} \\
\vdots \\
0 \\
\dot{b}\end{array}$ & 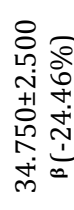 \\
\hline Aspirin & 100 & 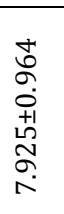 & 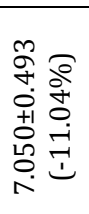 & $\begin{array}{l}\stackrel{8}{0} \\
\stackrel{1}{1} \\
+1 \\
\circ \\
\stackrel{0}{0} \\
\stackrel{+}{\sim}\end{array}$ & 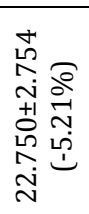 & 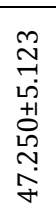 & 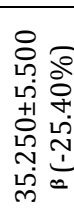 \\
\hline Dexamethazone & 1 & 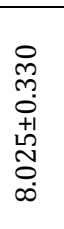 & 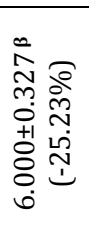 & 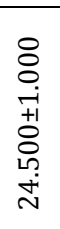 & 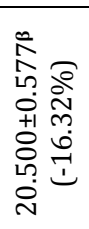 & 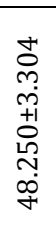 & 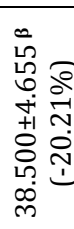 \\
\hline Control & & \begin{tabular}{l}
$n$ \\
0 \\
6 \\
0 \\
0 \\
01 \\
01 \\
\multicolumn{1}{l}{} \\
$\infty$ \\
$\infty$
\end{tabular} & $\begin{array}{l}0 \\
0 \\
0 \\
0 \\
0 \\
+1 \\
0 \\
0 \\
0 \\
0 \\
\infty \\
\infty\end{array}$ & 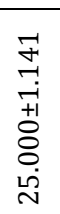 & 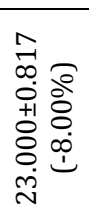 & 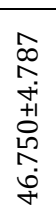 & 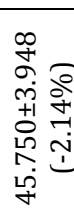 \\
\hline
\end{tabular}

Table 8: Effect of Extract on Haematological Indices in Arthritis

Results Are Expressed In Mean $\pm S D ; N=4$

$\left.{ }^{B}\right)(P<0.05)$ Compared To Control (Least Significant Difference Post Hoc Test) 


\begin{tabular}{|c|c|c|c|c|c|c|c|}
\hline \multirow{2}{*}{ 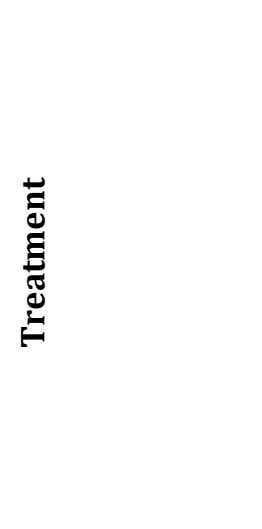 } & \multirow{2}{*}{ 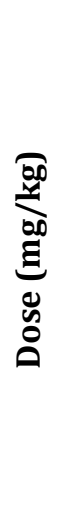 } & \multicolumn{2}{|c|}{ 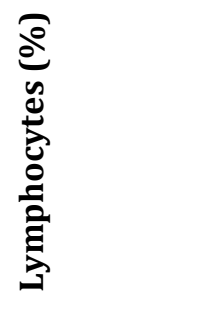 } & \multicolumn{2}{|c|}{ 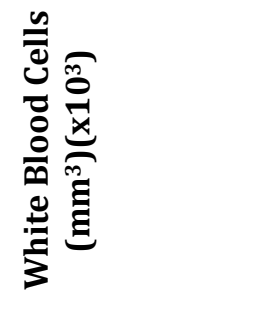 } & \multicolumn{2}{|c|}{ 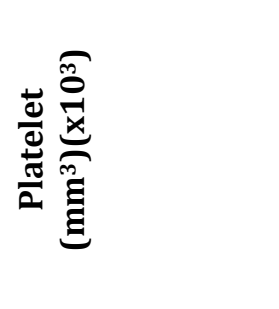 } \\
\hline & & 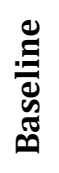 & 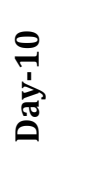 & 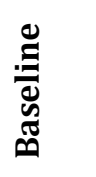 & $\begin{array}{l}\stackrel{0}{1} \\
\overrightarrow{1} \\
\overrightarrow{0}\end{array}$ & 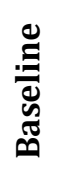 & 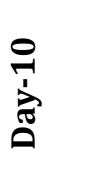 \\
\hline Extract & $\stackrel{\text { ̊ }}{\text { ¿ }}$ & 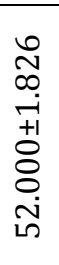 & 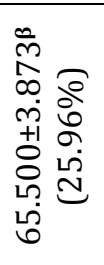 & $\begin{array}{l}\sigma \\
\sigma \\
b \\
\stackrel{2}{2} \\
+1 \\
+1 \\
\stackrel{1}{N} \\
\sigma \\
\infty \\
\infty\end{array}$ & 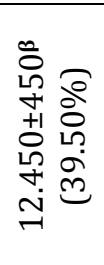 & 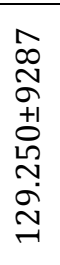 & 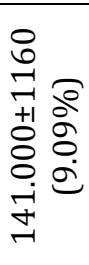 \\
\hline$"$ & 온 & $\begin{array}{l}8 \\
\text { ำ } \\
+ \\
+1 \\
+1 \\
\text { hn } \\
\text { กิ } \\
\text { ஸ่ }\end{array}$ & 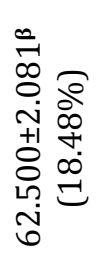 & 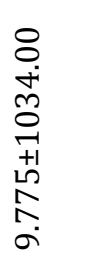 & 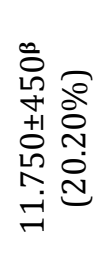 & 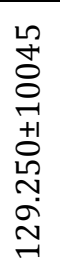 & 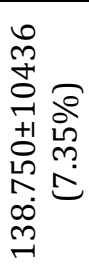 \\
\hline Aspirin & $\underset{-1}{\stackrel{8}{0}}$ & $\begin{array}{l}\stackrel{m}{+} \\
\stackrel{+}{+} \\
+ \\
+1 \\
\stackrel{8}{8} \\
\stackrel{1}{1} \\
\text { ஸ่ }\end{array}$ & 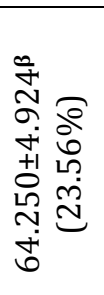 & 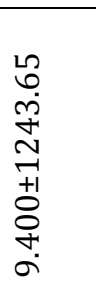 & 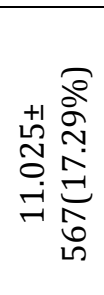 & 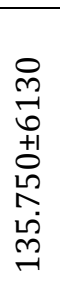 & 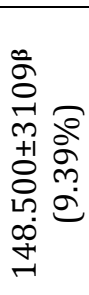 \\
\hline Dexamethazone & $r$ & $\begin{array}{l}-1 \\
0 \\
0 \\
+1 \\
0 \\
0 \\
10 \\
o ̛ ⿱ \\
\sigma\end{array}$ & 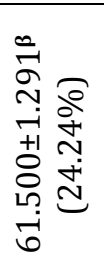 & 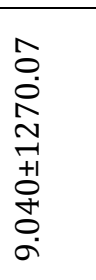 & 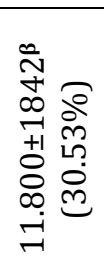 & 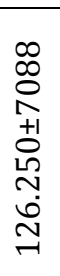 & 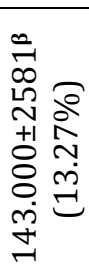 \\
\hline Control & & 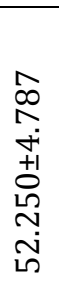 & 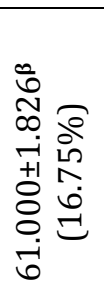 & $\begin{array}{l}0 \\
+ \\
0 \\
\dot{m} \\
\infty \\
0 \\
+1 \\
0 \\
0 \\
\infty \\
0 \\
\sigma\end{array}$ & 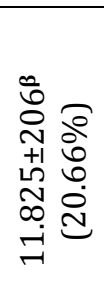 & 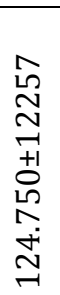 & 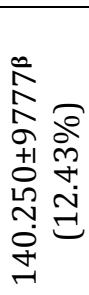 \\
\hline
\end{tabular}

Table 9: Effect of Extract on Haematological Indices in Arthritis Results Are Expressed in Mean \pm SD; $N=4$

$\left.{ }^{B}\right)(P<0.05)$ Compared to Control (Least Significant Difference Post Hoc Test) 


\begin{tabular}{|c|c|c|c|c|c|c|c|}
\hline \multirow{2}{*}{$\underset{\Xi}{\stackrel{\Xi}{\Xi}}$} & \multirow{2}{*}{ 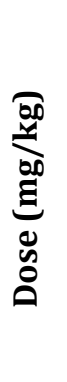 } & \multicolumn{2}{|c|}{ 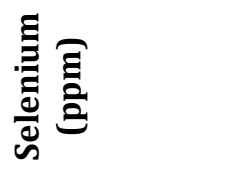 } & \multicolumn{2}{|c|}{ 彦高 } & \multicolumn{2}{|c|}{ 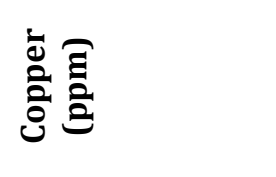 } \\
\hline & & 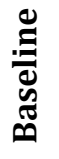 & $\begin{array}{l}\stackrel{0}{7} \\
\stackrel{7}{\vec{I}} \\
\stackrel{0}{0}\end{array}$ & 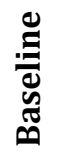 & $\begin{array}{l}\stackrel{0}{7} \\
\stackrel{\overrightarrow{7}}{\vec{t}} \\
0\end{array}$ & 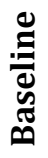 & 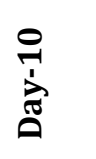 \\
\hline 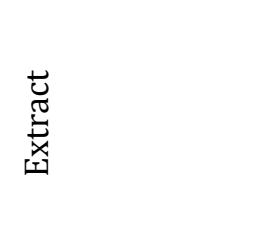 & 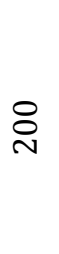 & $\begin{array}{l}\infty \\
\infty \\
\infty \\
i \\
+1 \\
+1 \\
0 \\
\stackrel{1}{0} \\
\stackrel{0}{0}\end{array}$ & 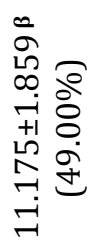 & $\begin{array}{l}\stackrel{m}{+} \\
\stackrel{+}{+} \\
+1 \\
\tilde{\sigma} \\
0 \\
\dot{+} \\
\dot{0}\end{array}$ & 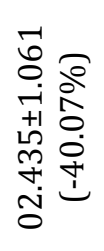 & 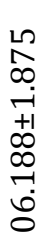 & 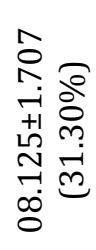 \\
\hline$=$ & 온 & 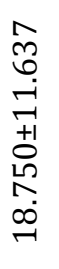 & 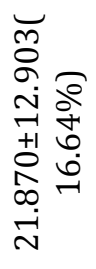 & \begin{tabular}{l}
0 \\
\multirow{+}{*}{} \\
0 \\
0 \\
+1 \\
0 \\
0 \\
ํ. \\
$\dot{0}$
\end{tabular} & 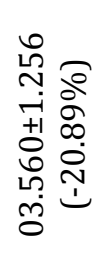 & 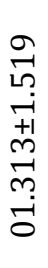 & 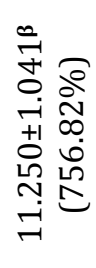 \\
\hline Aspirin & $\stackrel{8}{\circ}$ & 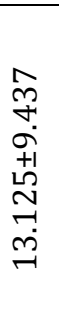 & 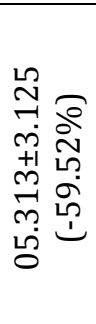 & $\begin{array}{l}\underset{N}{\infty} \\
\sim \\
\sim \\
+1 \\
\infty \\
\infty \\
\sim \\
\stackrel{\sim}{0}\end{array}$ & 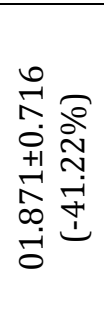 & 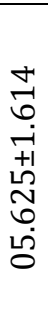 & 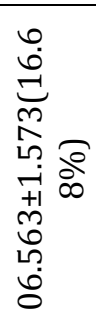 \\
\hline Dexamethazone & $-r$ & 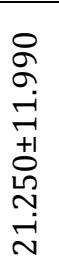 & 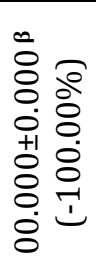 & $\begin{array}{l}8 \\
\infty \\
0 \\
+1 \\
m \\
\infty \\
\infty \\
\\
0\end{array}$ & 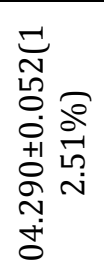 & 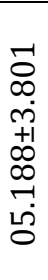 & 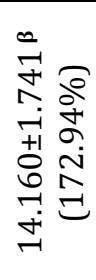 \\
\hline Control & ' & 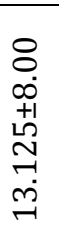 & 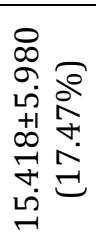 & 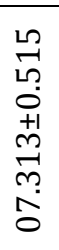 & 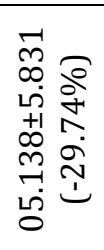 & 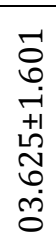 & 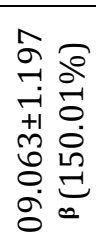 \\
\hline
\end{tabular}

Table 10: Effect of Extract on Serum Electrolytes in Arthritis Results Are Expressed in Mean \pm SD; $N=4$

$(B)(P<0.05)$ Compared to Control (Least Significant Difference Post Hoc Test)

\begin{tabular}{|c|c|c|c|c|}
\hline Treatment & $\begin{array}{c}\text { Concentration } \\
(\boldsymbol{\mu g} / \mathbf{m l})\end{array}$ & $\begin{array}{c}\text { Absorbance of } \\
\text { Hypotonic Solution } \\
\mathbf{( n m )}\end{array}$ & $\begin{array}{c}\text { Absorbance of } \\
\text { Isotonic Solution (nm) }\end{array}$ & $\begin{array}{c}\text { \% } \\
\text { Inhibition }\end{array}$ \\
\hline $\mathrm{EF}$ & 250 & $0.34 \pm 0.00$ & $0.11 \pm 0.00$ & 15.26 \\
\hline & 500 & $0.34 \pm 0.00$ & $0.14 \pm 0.00$ & 18.09 \\
\hline & 1000 & $0.26 \pm 0.01$ & $0.13 \pm 0.00$ & 50.45 \\
\hline $\mathrm{HF}$ & 250 & $0.36 \pm 0.00$ & $0.13 \pm 0.00$ & 11.91 \\
\hline & 500 & $0.34 \pm 0.00$ & $0.19 \pm 0.00$ & 23.66 \\
\hline $\mathrm{MF}$ & 1000 & $0.33 \pm 0.00$ & $0.21 \pm 0.00$ & 31.96 \\
\hline & 250 & $0.37 \pm 0.00$ & $0.13 \pm 0.00$ & 08.56 \\
\hline & 500 & $0.36 \pm 0.00$ & $0.15 \pm 0.00$ & 10.62 \\
\hline $\mathrm{DCMF}$ & 1000 & $0.36 \pm 0.00$ & $0.18 \pm 0.00$ & 11.88 \\
\hline & 250 & $0.36 \pm 0.00$ & $0.11 \pm 0.00$ & 09.19 \\
\hline & 500 & $0.29 \pm 0.00$ & $0.18 \pm 0.00$ & 44.55 \\
\hline
\end{tabular}




\begin{tabular}{|c|c|c|c|c|}
\hline Treatment & $\begin{array}{c}\text { Concentration } \\
(\boldsymbol{\mu g} / \mathbf{m l})\end{array}$ & $\begin{array}{c}\text { Absorbance of } \\
\text { Hypotonic Solution } \\
\mathbf{( n m )}\end{array}$ & $\begin{array}{c}\text { Absorbance of } \\
\text { Isotonic Solution (nm) }\end{array}$ & $\begin{array}{c}\text { \% } \\
\text { Inhibition }\end{array}$ \\
\hline & 1000 & $0.30 \pm 0.00$ & $0.12 \pm 0.00$ & 33.62 \\
\hline Diclofenac & 250 & $0.34 \pm 0.00$ & $0.13 \pm 0.00$ & 16.74 \\
\hline & 500 & $0.35 \pm 0.00$ & $0.14 \pm 0.00$ & 15.52 \\
\hline $\begin{array}{c}\text { Hypotonic } \\
\text { Control }\end{array}$ & 1000 & $0.32 \pm 0.00$ & $0.17 \pm 0.00$ & 30.52 \\
\hline Isotonic Control & -- & $0.38 \pm 0.00$ & -- & -- \\
\hline
\end{tabular}

Table 11: Effect of Fractions on Hypotonicity-Induced Haemolysis

$E F=$ Ethylacetate Fraction, $H F=N$-Hexane Fraction, $M F=$ Methanol Fraction, $D C M F=$ Dichloromethane Fraction. Results Are Expressed In Mean $\pm S D ; N=4$

\begin{tabular}{|c|c|c|c|}
\hline Treatment & Dose (mg/kg) & \multicolumn{2}{|c|}{ Serum Total Protein (U/l) } \\
\cline { 2 - 4 } & & Baseline & $\begin{array}{c}06.202 \pm 0.045 \\
\text { Day -10 } \\
(8.86 \%)\end{array}$ \\
\hline Extract & 200 & $05.697 \pm 0.629$ & $\begin{array}{c}06.485 \pm 0.279 \\
(2.32 \%)\end{array}$ \\
\hline Aspirin & 500 & $06.338 \pm 0.637$ & $\begin{array}{c}06.282 \pm 0.257 \\
(6.24 \%)\end{array}$ \\
\hline Dexamethazone & 100 & $05.913 \pm 1.026$ & $06.381 \pm 0.012$ \\
& 1 & $05.586 \pm 0.898$ & $(14.23 \%)$ \\
\hline Control & - & $07.165 \pm 0.877$ & $06.925 \pm 1.175$ \\
& & & $(-3.35 \%)$ \\
\hline
\end{tabular}

Table 12: Effect of Extract on Serum Total Protein Concentration

Results Are Expressed In Mean $\pm S D ; N=4$

Mean Values with (B) Superscripts across the Row Compared with Baseline Are Considered Significant $(P<0.05)$

\begin{tabular}{|c|c|c|c|}
\hline \multirow[t]{2}{*}{ Treatment } & \multirow[t]{2}{*}{ Dose (mg/kg) } & \multicolumn{2}{|c|}{ Serum Uric Acid (U/l) } \\
\hline & & Baseline & Day -10 \\
\hline Extract & 200 & $03.983 \pm 1.180$ & $\begin{array}{c}04.025 \pm 0.174 \\
(1.06 \%)\end{array}$ \\
\hline " & 500 & $03.279 \pm 1.911$ & $\begin{array}{c}06.404 \pm 1.746 \\
(95.30 \%)\end{array}$ \\
\hline Aspirin & 100 & $04.486 \pm 1.999$ & $05.162 \pm 1.954(15.07 \%)$ \\
\hline Dexamethazone & 1 & $02.847 \pm 2.457$ & $\begin{array}{c}03.030 \pm 0.175 \\
(6.43 \%)\end{array}$ \\
\hline Control & - & $03.854 \pm 0.701$ & $\begin{array}{c}03.945 \pm 1.469 \\
(2.36 \%)\end{array}$ \\
\hline
\end{tabular}

Table 13: Effect of Extract on Serum Uric Acid Concentration

Results Are Expressed In Mean $\pm S D ; N=4$

Mean Values with (B) Superscripts across the Row Compared with Baseline Are Considered Significant $(P<0.05)$

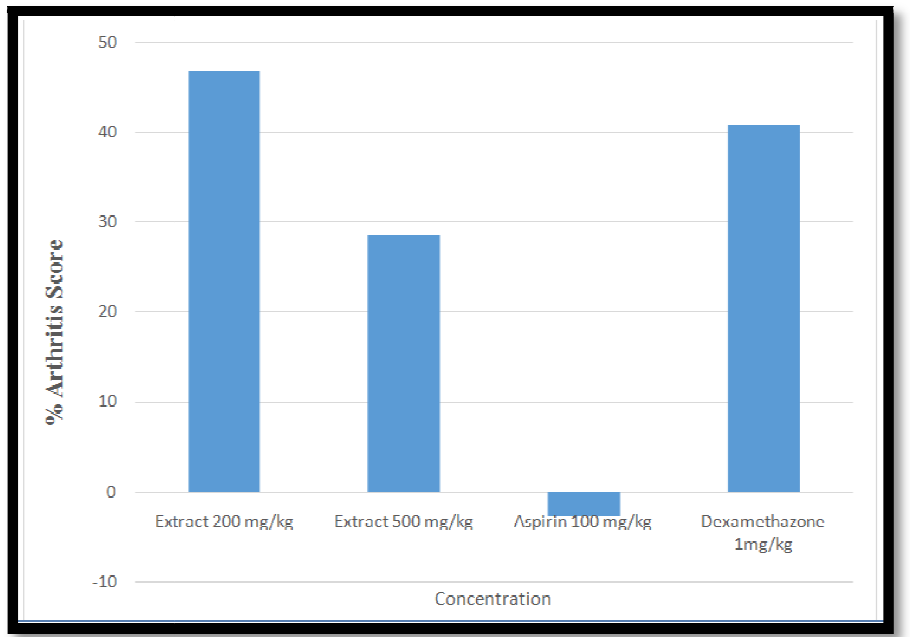

Figure 1: Percentage Inhibition of Arthritis (AUC) 
The area under the curve (AUC) of the overall arthritis score is computed as a measure for the arthritis severity per animal during the 10 days of drug treatment

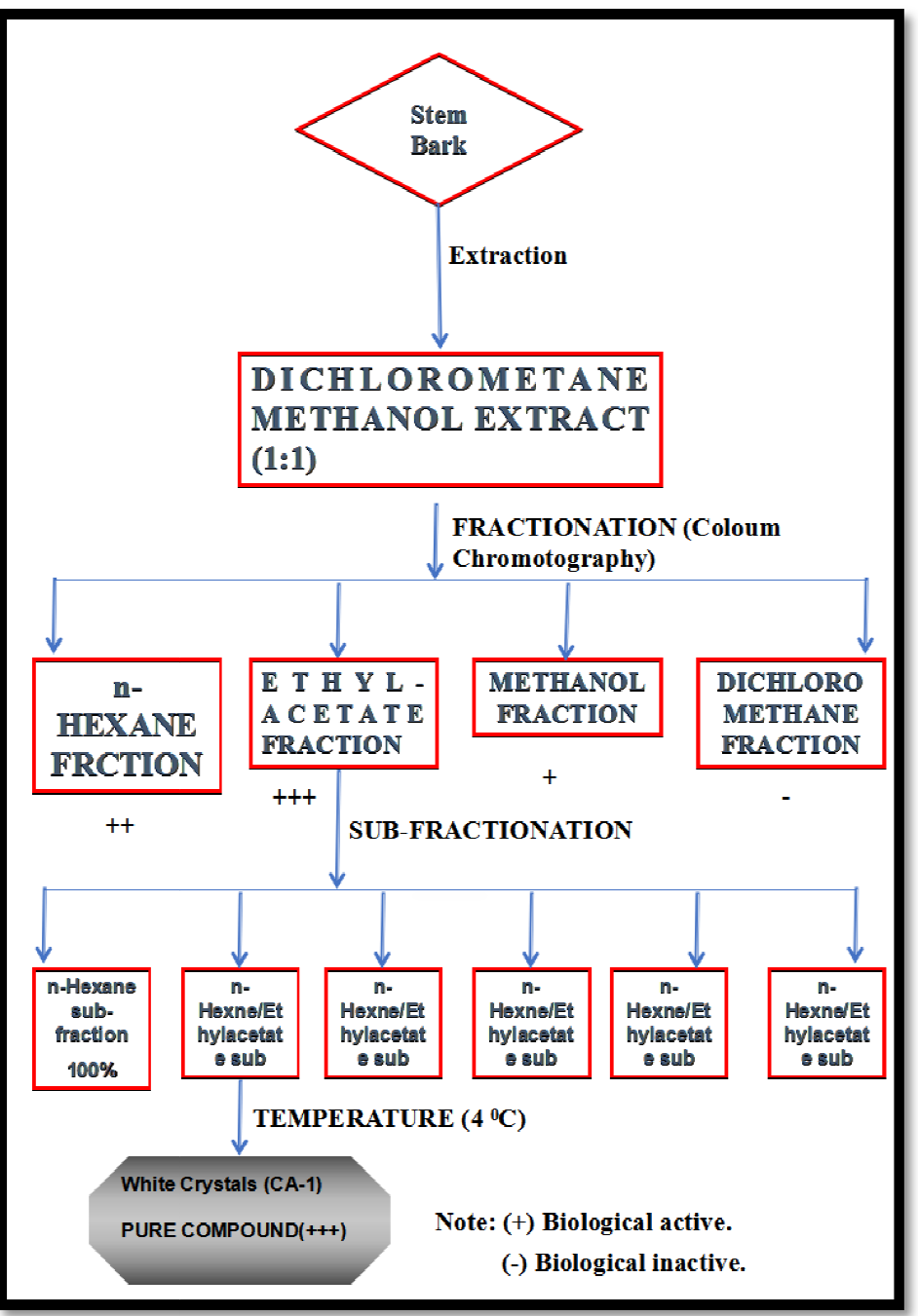

Figure 2: Flow Chart for the Extraction and Fractionation of the Anti-Inflammatory Constituent of the Extract 